\title{
August 12 Highlights
}

\section{The site of the lesions in "vestibular neuritis"}

Murofushi et al. studied the site of lesions in "vestibular neuritis" using galvanic vestibular evoked myogenic potentials. Among the 11 patients diagnosed with vestibular neuritis, eight showed a neuritis pattern whereas three showed a labyrinthitis pattern.

see page 417

Commentary by Michael Halmagyi and James Colebatch

It is over a decade since Neurology published the first report of a short latency vestibulo-collic reflex we called the vestibular evoked myogenic potential (VEMP), recordable from anterior neck muscles, specifically the sternomastoid, in response to loud clicks. ${ }^{1}$ Since then, the VEMP has been studied in vestibular laboratories worldwide and has been shown to have application in the assessment of a range of vestibular disorders, including superior semicircular canal dehiscence, Ménière disease, multiple sclerosis, brainstem infarction, vestibular neuritis, and vestibular schwannomas. $^{2}$ The definition of this vestibulo-collic reflex pathway has allowed the development of other novel methods of vestibular activation such as head tapping, mastoid bone vibration, and the technique used in this article, short duration galvanic (DC) currents. A galvanic current applied to the mastoid directly activates vestibular nerve endings. Murofushi and coworkers have produced much of the new clinical work in the last 5 years on VEMP. They previously reported that galvanic VEMP can separate vestibular nerve (retro- labyrinthine) lesions from vestibular end-organ (labyrinthine) lesions. They now turn their attention to defining the level of the pathology in vestibular neuritis. Sudden, isolated, total or subtotal, unilateral loss of vestibular function can occur during viral infections such as mumps and herpes zoster and perhaps herpes simplex. As a result, this form of unilateral loss of vestibular function has, like sudden unilateral loss of facial nerve function, been attributed to the direct or indirect effects of a viral infection of the vestibular nerve, "vestibular neuritis."3 But, perhaps unsurprisingly, there is little pathologic evidence of neuritis in the vestibular nerve. Some patients with vestibular neuritis develop benign positional vertigo, a syndrome that actually indicates end-organ involvement. Nonetheless, uncertainty remains as to the exact site or sites of lesion.

In this issue of Neurology, Murofushi et al. present click and galvanic VEMP in patients with severe vestibular neuritis, studied within a month of onset, who had all lost the click VEMP on the affected side. They found that whereas most had also lost the galvanic VEMP, implying involvement of the vestibular nerve, three had preserved galvanic VEMP, implying that the vestibular nerve remained intact. This indicates that at least in some patients, the lesion is primarily in the labyrinth. Although their results show that most patients with vestibular neuritis have evidence of impairment of the vestibular nerve, even this could be an "upstream" effect. The additional involvement of the end organ-the labyrinth itself-cannot be excluded. It is not clear therefore whether these two patterns are indicative of two different types of pathology or part of a continuum. In light of their new results, however, the rather ungainly term "vestibular neuro-labyrinthitis" seems more accurate than "vestibular neuritis."

\section{References}

1. Colebatch JG, Halmagyi GM. Vestibular evoked potentials in human neck muscles before and after unilateral vestibular deafferentation. Neurology 1992;42:1635-1636.

2. Colebatch JG. Vestibular evoked potentials. Curr Opin Neurol 2001;14:21-26.

3. Baloh RW. Vestibular neuritis. N Engl J Med 2003;348:1027-1032. 


\section{$A_{2 A}$ receptor inhibition in Parkinson's disease}

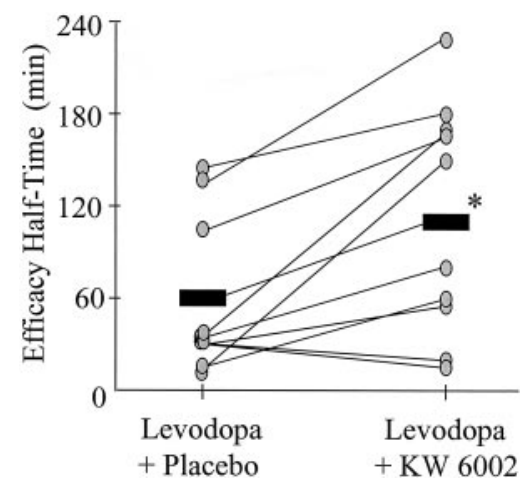

\section{Randomized trial of istradefylline in advanced PD}

Pharmacologic blockage of striatal adenosinergic $A_{2 \mathrm{~A}}$ receptors has been proposed as adjunctive treatment of Parkinson's disease. In a randomized, blinded study, Bara-Jimenez et al. found that the $\mathrm{A}_{2 \mathrm{~A}}$ antagonist KW 6002 potentiates and prolongs the antiparkinsonian action of levodopa, but with less severe dyskinesia.

see page 293

\section{Neuropathology in restless legs syndrome: Further evidence for abnormal iron metabolism}

In a neuropathological study of individuals with primary RLS, Connor et al. found

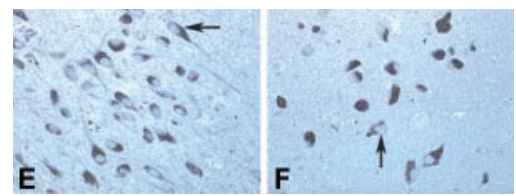

(E) Transferrin receptor immunoreaction (blue) on most brown neuromelanin-containing cells (control). (F) In RLS, product for $T f$ receptor is minimal. that transferrin receptor expression on neuromelanin cells is less than expected given the profile of iron deficiency in the substantia nigra. No other histopathology was observed in the restless legs syndrome brains.

see page 304

\section{Cycad neurotoxins are biomagnified in Guam flying foxes}

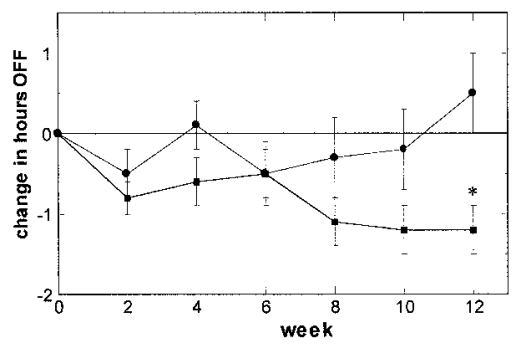

Hours OFF on home diaries. Placebo (circles), istradefylline (squares).

Hauser et al. report results of a 12-week, blinded, randomized, placebo-controlled, exploratory study of istradefylline in PD subjects with both motor fluctuations and peak-dose dyskinesias. Istradefylline was generally well tolerated and reduced $\mathrm{OFF}$ time as assessed by home diaries.

see page 297

In the editorial accompanying these two articles, Andrew Feigin focuses attention on the need to have better symptomatic treatments for patients with advanced PD. He notes that animal model data have supported the ability of adenosine $A_{2 A}$ receptor antagonists to enhance dopamine benefit without worsening dyskinesias. Whereas the use of subthalamic nucleus deep brain stimulation has raised the standard for medical therapies in advanced $P D$, the results of these two trials are encouraging. Moreover, adenosine $A_{2 A}$ antagonists may have the additional benefit of being neuroprotective.
Banack and Cox report that flying foxes from Guam have extraordinarily high levels of the cycad neurotoxin BMAA. This finding is consistent with their hypothesis that ALS-PDC among the Chamorro people of Guam is associated with traditional feasting on flying foxes.

see page 387

The accompanying editorial by Carmel Armon reflects upon the important clue to ALS pathogenesis offered by the Guamanian disorder of anterior horn cells. Regarding whether it is BMAA or some other cycad toxin that causes Guamanian $A L S$, he notes that in order to confirm a role for consumption of flying foxes (a type of bat) it will be necessary to show the population that was consumed-the high concentration of $B M A A$ in the museum specimens may have been the reason why these specific bats became museum exhibits. It is also necessary to show that toxin concentrations in the edible parts of flying foxes are as high as those in the skin, and that they are not reduced by the preparation of flying foxes for consumption. Finally, it would be necessary to confirm that the individuals affected by ALS/PDC on Guam actually consumed contaminated flying foxes and that humans could consume them without experiencing acute toxicity. Finally, it would be necessary to show if they accumulate in affected individuals, more than in unaffected individuals, and how toxins consumed in concentrations not causing acute toxicity might cause ALS years later. 


\section{Central Horner's syndrome and contralateral ataxic hemiparesis}

Rossetti et al. studied nine patients with a crossed syndrome of

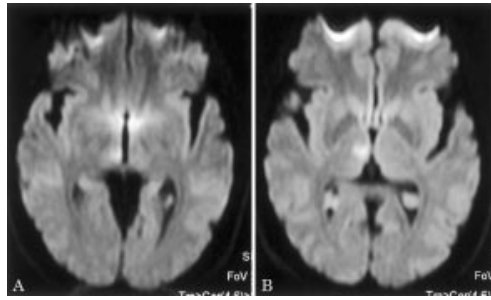

Ischemic lesion in the right paramedian thalamic territory, extending to the rostral paramedian mesencephalon (DW-MRI).

\section{Inflammatory change in myopathy with GNE mutations}

Yabe et al. reported two siblings with distal myopathy with rimmed vacuoles

\section{Polymyositis (PM): an overdiagnosed entity?}

Based on clinical, laboratory, and histopathologic criteria, van der Meulen et al. diagnosed 165 patients with myositis (inclusion body myositis excluded) as follows: polymyositis 9 , dermatomyositis 59 , unspecified myositis (perimysial/perivascular infiltrates, no PM or DM) 65 , possible myositis (necrotizing myopathy, no inflammatory infiltrates) 32. At follow-up, five of the nine patients with PM had typical features of inclusion body myositis.

see page 316

\section{Epilepsy risk factors and cortical dysplasia}

Patients with medically refractory temporal lobe epilepsy (TLE) frequently have risk factors for epilepsy such as febrile convulsions (FC). Porter et al. found that the majority of children with refractory TLE and a history of FC, who were treated with surgery, actually had cortical dysplasia in temporal neocortex.

see page 365

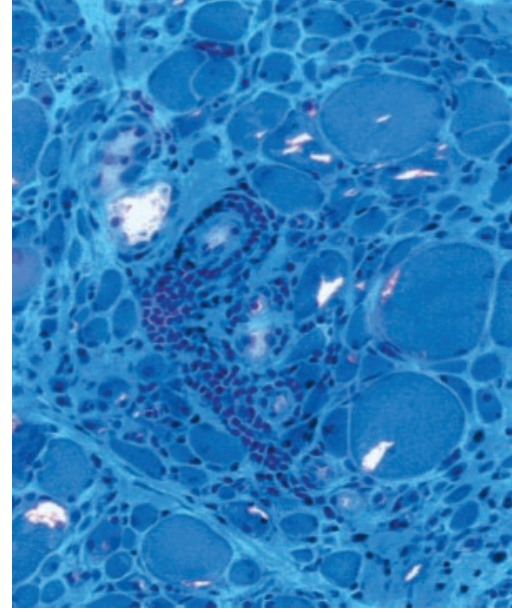

Rimmed vacuolated muscle fibers and perivascular and endomysial mononuclear cell inflammation.
(DMRV) with GNE mutations. Inflammation, uncommon in DMRV, was observed in the connective tissue and between muscle fibers.

see page 384

The editorial by Amato and Griggs, which accompanies the articles by van der Meulen et al. and Yabe et al., notes that polymyositis remains a diagnosis of exclusion. The list of exclusions continues to lengthen. As newly recognized diseases such as dysferlinopathies and GNE mutations are also found to present with a polymyositis phenotype, polymyositis as a separate disease entity may become rare or cease to exist.

see page 288

\section{ID migraine ${ }^{\mathrm{TM}}$ : A screener for improving migraine recognition}

Lipton et al. developed and validated a three-item migraine screener in 563 patients with headache presenting for routine primary care. Those who had two of three cardinal migraine features on the screener (headache-related disability, nausea, and photophobia) had a 93\% chance of having a migraine diagnosis assigned by a independent headache expert. The simplicity and brevity of the screener, when coupled with its reliability, sensitivity, and specificity, suggest that it could improve migraine recognition.

see page 375 


\section{Neurology}

\section{August 12 Highlights}

Neurology 2003;61;283-285

DOI 10.1212/WNL.61.3.283

This information is current as of August 11, 2003

\section{Updated Information \&} Services

References

Permissions \& Licensing

Reprints including high resolution figures, can be found at: http://n.neurology.org/content/61/3/283.full

This article cites 3 articles, 1 of which you can access for free at: http://n.neurology.org/content/61/3/283.full\#ref-list-1

Information about reproducing this article in parts (figures,tables) or in its entirety can be found online at:

http://www.neurology.org/about/about_the_journal\#permissions

Information about ordering reprints can be found online:

http://n.neurology.org/subscribers/advertise

Neurology ${ }^{\circledR}$ is the official journal of the American Academy of Neurology. Published continuously since 1951, it is now a weekly with 48 issues per year. Copyright . All rights reserved. Print ISSN: 0028-3878. Online ISSN: 1526-632X.

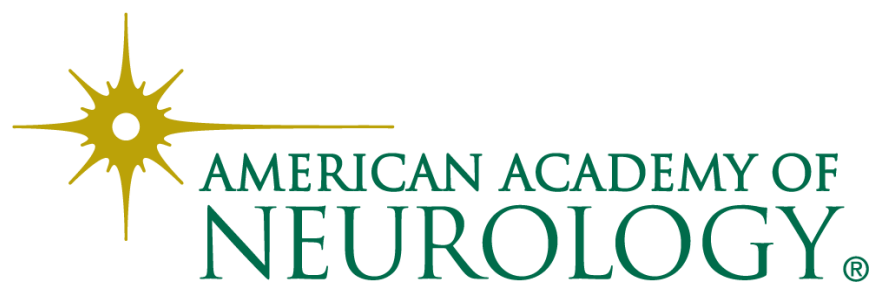

